\title{
O assédio moral nas organizações: as consequências dessa prática para a sociedade
} Workplace moral harassment: its consequences for society

\author{
Carla de Fátima Nascimento Queiroz de Paula ${ }^{a}$ \\ (1) https://orcid.org.0000-0001-6872-5022 \\ Ana Carolina de Gouvêa Dantas Motta \\ (1) https://orcid.org.0000-0001-5918-6274 \\ Rejane Prevot Nascimento ${ }^{b}$ \\ (D) https://orcid.org/0000-0002-5242-9509
}

Resumo: $\mathrm{O}$ assédio moral tem sido uma prática recorrente nos ambientes de trabalho. Entre os principais impactos, observa-se a desvalorização do trabalho, seguida do baixo desempenho profissional, enquanto na vida pessoal, as condutas abusivas podem levar o trabalhador ao adoecimento físico e psíquico. A dificuldade para a comprovação dos fatos dificulta a penalização dos autores desses crimes, dessa maneira, perpetuando a impunidade e reforçando a indevida naturalização dos casos de assédio moral.

Palavras-chave: Assédio Moral. Impunidade. Sobrecarga de Trabalho. Condições de Trabalho.

\begin{abstract}
Moral harassment is a persistent pattern of mistreatment from others in the workplace. Among the main impacts, there is the devaluation of work, followed by low professional performance, while in personal life, abusive behaviors can lead the worker to physical and psychological illness. The difficulty in proving the facts makes it difficult to penalize the perpetrators of these crimes, thus perpetuating impunity and reinforcing the undue naturalization of cases of moral harassment.
\end{abstract}

Keywords: Moral Harassment. Impunity. Work Overload. Work Conditions.

aCentro Universitário de Desenvolvimento do Centro-Oeste (UNIDESC), Luziânia /GO, Brasil.

bUniversidade do Grande Rio (Programa de Pós-Graduação em Administração/UNIGRANRIO), Duque de Caxias/RJ, Brasil.

Recebido: 2/4/21 - Aprovado: 14/6/21 


\section{Introdução}

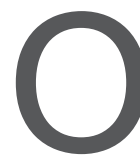

assédio moral nas relações de trabalho pode ser definido como repetidos comportamentos, ações e práticas hostis dirigidos a um ou mais trabalhadores de forma consciente ou inconsciente, que podem trazer danos à integridade psíquica ou física do indivíduo, além de interferir no desempenho e no ambiente de trabalho (Hirigoyen, 2010). A violência expressa nessas ações e os comportamentos hostis fazem parte das relações humanas desde os tempos mais remotos, ou seja, a violência moral pode ser considerada tão antiga quanto o próprio trabalho. Entretanto, é a partir da década de 1980 que as pesquisas ganham maior visibilidade e o assédio moral passar a ser estudado como uma forma de violência perversa nas relações de trabalho (Nunes, 2016).

A pressão do mercado capitalista impôs a adoção de modelos de gestão pautados na força de trabalho e na produtividade. Barreto e Heloani (2015) apontam que esses modelos afetam diretamente os trabalhadores, pois aumentam o nível de exigência para torná-los mais competitivos e produtivos, ao passo que otimizam o processo e consequentemente reduzem os gastos das empresas. A redução de gastos é nitidamente perceptível com as terceirizações e a precarização das condições de trabalho, associadas aos baixos salários e às jornadas prolongadas. Barreto (2000) e Santos, Guimarães-Iosif e Chaves (2018) destacam que as novas formas de organizar o trabalho e a produção implicaram vários desacertos para o trabalhador, dentre eles: a quebra de direitos sociais, crescimento do setor informal, aumento do subemprego, aumento do desemprego, aumento da miséria, dentre outros. Além da cobrança diária por um espírito competitivo, perfil multifuncional, flexível e disposto, o que interfere inclusive na personalidade do indivíduo (Barreto, 2000; Bosi, 2011; Barreto; Heloani, 2015).

Portanto, o presente artigo visa contribuir para a apresentação dos conceitos acerca do assédio moral nas organizações, de modo a reafirmá-lo como uma prática cotidiana de violência no ambiente de trabalho, 
bem como analisar os impactos em forma de sofrimento na vida pessoal e profissional de trabalhadores.

\section{Assédio moral no ambiente organizacional e suas origens}

As pesquisas acadêmicas sobre o assédio moral começaram a ganhar maior visibilidade na década de 1990, embora Freitas (2001) tenha destacado que o problema do assédio no trabalho seja considerado tão antigo quanto o próprio trabalho. Os resultados das primeiras pesquisas da época mostraram que o assédio moral é um fenômeno destrutivo do ambiente de trabalho, e que seus impactos não só reduziam a produtividade e aumentava o absenteísmo, como também geravam danos psicológicos, alguns irreversíveis para a vida do trabalhador (Nunes, 2016; Silva, 2016).

Aliado à evolução das pesquisas sobre o tema, o fenômeno da globalização sujeitou forçosamente toda uma sociedade trabalhadora a se transformar. Dentre as mudanças impostas, a necessidade de reorganização do mercado, bem como de suas relações com o trabalho, gerou um senso de competitividade não só entre as empresas, mas especialmente entre os trabalhadores. Portanto, todo processo que envolve mudança requer uma atitude transformadora por parte dos indivíduos envolvidos, entretanto, nem sempre as circunstâncias intrínsecas ao processo transformador serão positivas, sendo em muitos casos negativas, por exemplo, situações de concorrência entre os pares (Mancebo, 2010; Mancebo; Silva Júnior; Oliveira, 2018; Santos; Guimarães-Iosif; Chaves, 2018).

Heloani (2011) destaca que cada vez mais a rivalidade e a competição nos ambientes organizacionais têm sido fomentadas pela própria empresa, e que situações corriqueiras acabam por atingir a dignidade do trabalhador com graves consequências no âmbito de suas relações de trabalho. Nesse contexto, o assédio moral vem ganhando cada vez mais notoriedade no campo do ambiente organizacional. 
A partir do conceito de assédio moral proposto por Hirigoyen (2010), que é toda e qualquer conduta abusiva que se manifesta notadamente por comportamentos, palavras, atos, gestos, que podem causar danos à personalidade, à dignidade ou à saúde física ou psíquica de uma pessoa, colocando em risco ou degradando o emprego e as relações de trabalho, o clima de rivalidade e concorrência por cargos ou posições contribui para o fomento de situações de assédio moral.

Destaca-se que, frente ao mercado tão instável e desafiador, a conquista e a permanência no emprego têm exigido um perfil de trabalhador cada vez mais detentor não só de competências técnicas, mas também de um "forte espírito competitivo" e de "agressividade". Esses termos, utilizados comumente nos ambientes organizacionais, incitam comportamentos violentos, abusivos e humilhantes dentro das empresas, sendo justificados em prol da ascensão das metas e da capacidade produtiva individual (Freitas; Heloani; Barreto, 2008; Rodrigues, 2013; Damasceno, 2015; Nunes, 2016; Tavares, 2017).

Heloani (2011) corrobora os achados dos pesquisadores supracitados, afirmando que essa competitividade instaurada dentro das organizações acaba por levar o relacionamento entre os trabalhadores a se tornar desrespeitoso, e comumente a própria organização é complacente com o insulto e o abuso. Essa atmosfera permissiva facilita o surgimento de ofensas, até mesmo sádicas, justificadas, por exemplo, para punir os profissionais que não atingiram suas metas. Procedimentos "inocentes" ou "brincadeiras" que, na verdade, acabam por se constituir em práticas institucionalizadas de assédio moral tornaram-se verdadeiros eventos humilhantes dentro das organizações (Hirigoyen, 2010; Rodrigues; Freitas, 2014; Damasceno, 2015).

A título de ilustração, o pesquisador Roberto Heloani (2011) publicou um artigo denominado "A dança da garrafa: assédio moral nas organizações". Pelo título do texto, é possível ser identificadas as atrocidades praticadas no ambiente de trabalho de empresas brasileiras, impostas aos seus funcionários. $\mathrm{O}$ autor revela ainda que é comum a vivência de 
situações vexatórias ou obscenas dentro das organizações, como literalmente obrigar os trabalhadores a dançarem a "dança da garrafa" ou, até mesmo, se submeterem a insultos e humilhações, como se vestirem de fantasias e desfilar pela empresa ou maquiarem-se de forma ridícula.

Dentre as situações constrangedoras, o artigo revela ainda atividades desempenhadas pelos funcionários das empresas, como fazer flexões de braço recebendo xingamentos ou sujeitarem-se a ser chicoteados como forma de punição. Vestir camisetas com dizeres ofensivos, usar uma tartaruga ou âncora como pingente, sugerindo que aquele trabalhador é "lento" ou afundará a empresa, entre muitos outras, são algumas das situações às quais os funcionários são rotineiramente submetidos, ações que atingem a dignidade do trabalhador e podem colocar em risco a sua integridade emocional e profissional (Heloani, 2011; Nunes, 2016; Silva, 2016; Dantas, 2018).

Bradaschia (2007) afirma que o assédio moral inicia de modo "sutil" e "inocente", em tom de brincadeira ou de uma atitude descontraída entre os colegas de trabalho e seus superiores, entretanto, esse comportamento acaba por contribuir com a propagação da prática do assédio moral dentro das organizações, por se tornar um hábito e por não haver a censura de tais comportamentos. Assim, as vítimas optam por não denunciar e acabam por aceitar, às vezes involuntariamente, as insinuações e as chacotas, que mais tarde tendem a piorar (Damasceno, 2015; Dantas, 2018).

Para Hirigoyen (2010), Bradaschia (2007), Heloani (2011) e Rodrigues e Freitas (2014), no primeiro momento, as pessoas envolvidas não querem mostrar-se ofendidas, e levam na esportiva as desavenças e os maus-tratos. Em seguida, esses ataques se multiplicam e a vítima é seguidamente acuada, colocada em situação de inferioridade, e submetida a manobras gerenciais hostis e degradantes, por longos períodos. Ou seja, a repetição dos vexames e das humilhações públicas, sem qualquer repreensão, torna o fenômeno do assédio moral destruidor e avassalador (Silva, 2016; Tavares, 2017). 
Nesse contexto, Hirigoyen (2010), referência internacional sobre assédio moral nas organizações, classifica-o em quatro categorias, apresentadas na Tabela 1, a seguir:

Tabela 1. Categorias do assédio moral nas organizações.

\begin{tabular}{|c|c|}
\hline Tipo de assédio & Descrição \\
\hline Isolamento & $\begin{array}{l}\text { Ignora-se a presença do trabalhador, impossibilitando o diálogo; se tenta } \\
\text { falar, é interrompido; a comunicação com ele é feita por escrito; seu pedido } \\
\text { de entrevista é negado pela direção. }\end{array}$ \\
\hline Dignidade violada & $\begin{array}{l}\text { Gestos de desprezo e insinuações desdenhosas para com a vítima; rumo- } \\
\text { res sobre sua sanidade mental; zombarias caricaturais sobre seu aspecto } \\
\text { físico, nacionalidade, crenças religiosas ou convicções políticas; atribuição } \\
\text { de trabalhos degradantes; injúrias. }\end{array}$ \\
\hline $\begin{array}{l}\text { Atentado às } \\
\text { condiçõos de } \\
\text { trabalho }\end{array}$ & $\begin{array}{l}\text { Não transmitir informações úteis para a realização de tarefas; contestar } \\
\text { sistematicamente decisões tomadas pelo trabalhador; criticar seu trabalho } \\
\text { de maneira injusta ou exagerada; privá-lo do acesso aos instrumentos de } \\
\text { trabalho; retirar o trabalho que lhe compete; dar sempre novas tarefas, } \\
\text { muitas inferiores, às suas competências; pressioná-lo para que não faça } \\
\text { valer os seus direitos; agir de modo a impedir que obtenha promoção; atri- } \\
\text { buir à vítima, contra a vontade dela, trabalhos perigosos; dar instruções } \\
\text { impossíveis de executar. }\end{array}$ \\
\hline $\begin{array}{l}\text { Violência verbal, } \\
\text { física e sexual }\end{array}$ & $\begin{array}{l}\text { Ameaças de violência física que podem chegar à agressão; empurrões e } \\
\text { gritos; invasão de privacidade por meio de telefonemas ou cartas; espio- } \\
\text { nagem e estragos em bens pessoais; agressões sexuais. }\end{array}$ \\
\hline
\end{tabular}

Fonte: Hirigoyen (2010).

Para a autora, as modalidades apresentadas na tabela podem ocorrer de maneira combinada, ou seja, duas ou mais situações ao mesmo tempo, o que torna o resultado ainda mais contundente e traumático para o trabalhador, que nesse caso é a vítima.

Freitas (2001) traz em suas pesquisas relatos de situações que acontecem nos ambientes corporativos, também fundamentados nas categorias de assédio elencadas por Hirigoyen (2010), em especial situações de assédio do tipo: dignidade violada e violência verbal. Freitas (2001) descreve comportamentos de chefes medíocres, sádicos e histéricos, que gritam, lançam objetos sobre seus funcionários, deturpam fatos e acusam colegas por perda de documentos, logo, criam armadilhas para 
laçar e tragar seus subordinados no intuito prioritário de humilhá-los e desprezá-los.

Heloani (2011) acrescenta ao afirmar que o assédio moral é intencional e que a pessoa que o pratica tem noção do que está fazendo. Freitas (2001) confirma e evidencia que o ato intencional do assediador é fazer com que a pessoa se sinta minimizada e menosprezada, sendo submetida a frases do tipo: "viu como eu tinha razão, você é um incompetente!", "eu disse que você não daria conta do recado". Diante desse contexto, é natural que a vítima se sinta abalada e seu rendimento seja menor ou inferior que o esperado, o que reforça os achados de Heloani (2011) quando diz que o ato é premeditado e o assediador já sabe que isso gerará um resultado diante dos demais colegas. Nesse sentido, a partir da prática de assédio no ambiente de trabalho como forma de exemplo, o assediador faz com que seus subordinados creiam ter sido necessária e merecida tal conduta.

Portanto, é prática comum os colegas não tomarem partido do assediado. Na maioria dos casos, os demais colegas ignoram a situação ou, no máximo, conversam entre si, sem deixar o assunto tomar grandes proporções, normalmente terminam suas conversas com frases do tipo: "eles que são brancos que se entendam...", ou "é uma briga de titãs... nada temos a fazer..." (Freitas, 2001). Arraigado a esse contexto, o assédio moral também é fundamentado na inveja, em inimizades pessoais e conflitos entre os próprios colegas de trabalho (Hirigoyen, 2010).

No cotidiano das organizações, a origem da violência e do assédio pode nascer do encontro entre a inveja do poder e a perversidade. Independentemente da origem do assédio, ele pode ser considerado um processo ardiloso e perverso, que visa bloquear psicologicamente a capacidade de defesa da vítima. Obviamente que esse bloqueio provocará uma série de mudanças comportamentais da vítima, afetando em especial a autoestima, que resultará na sensação de inutilidade. Este conjunto de emoções vagarosamente irá minar a dignidade e o autorrespeito do assediado. Inevitavelmente, o assédio quando não enfrentado acaba por desestabilizar 
as emoções do assediado, podendo levá-lo a desenvolver doenças físicas ou psicossomáticas graves ou até mesmo conduzir a vítima ao suicídio (Hirigoyen, 2010; Freitas, 2001; Heloani, 2011; Moreira, 2017).

Nesse contexto, o assédio moral no ambiente de trabalho pode acontecer de diferentes maneiras, sendo difícil para a vítima perceber essa prática logo no início. Para Hirigoyen (2010) e Freitas (2001), o assédio pode ocorrer entre os pares, sendo aquele que acontece entre colegas do mesmo nível hierárquico da esfera organizacional da empresa, também conhecido como assédio horizontal. As situações que motivam esse tipo de prática são diversas. Freitas, Heloani e Barreto (2008) destacam que é comum a disputa pela obtenção de um mesmo cargo ou de uma promoção. As características, as habilidades profissionais e a competência podem ser consideradas razões para inflamar e incitar o assédio entre os pares. Além desses fatores, outros como diferentes culturas, etnias, níveis de escolaridade e faixas etárias, deficiências físicas, preferências sexuais, políticas e/ou religiosa podem servir de pretexto para desencadear agressões que futuramente poderão se transformar em combustível para novas práticas de assédio moral entre colegas (Hirigoyen, 2010).

Quando o assédio ocorre entre os pares, é comum que a empresa não tome partido de nenhuma parte. Normalmente, a empresa opta por deixar a situação acontecer, julgando ser comum, na expectativa de que ela seja solucionada por si só. Já em outros casos, a empresa nem reconhece a existência do assédio horizontal, exceto quando a vítima reage. Nessas situações, a postura da empresa pode ser sutil, agindo como mediadora do problema, ou hostil, optando pelo afastamento do trabalhador de suas atividades por determinado período. A opção pelo afastamento nem sempre é a mais adequada, visto que acaba por afetar a produtividade da empresa. Portanto, às vezes a melhor alternativa é mudar o funcionário de setor em vez de assumir a postura de assédio e combater tal prática (Hirigoyen, 2010; Heloani, 2011; Damasceno, 2015; Tavares, 2017). 
Freitas (2001) destaca ainda que as agressões entre os pares também podem ser oriundas das inimizades pessoais ou pautadas na expectativa de se valorizar a partir das amizades com os dirigentes da empresa. Neste último caso, algumas vítimas acabam por pedir apoio do superior na tentativa de resolver a prática de assédio horizontal. Mas, geralmente, atitudes como essa podem gerar o efeito contrário, ou seja, reforçar o problema entre os pares em vez de solucioná-lo, abrindo assim espaço para acusações de favoritismo ou protecionismo e, até mesmo, margem e precedentes para intepretações de interesse sexual entre chefe e subordinado, o que pode caracterizar o assédio sexual (Matos, 2016; Tavares, 2017).

Outra modalidade de assédio moral no trabalho é aquele praticado pelo chefe, também denominado como assédio vertical descendente. Segundo as pesquisas de Hirigoyen (2010), esse constitui o caso mais comum de assédio moral nas organizações. A autora relata que as chefias acabam dando vazão às suas frustrações ou fantasias de onipotência para assediar seus subordinados, usando violência verbal e/ou física com abuso de poder, dificultando as condições de trabalho de seus subordinados, além de se utilizarem constantemente das ameaças de demissão como estratégia de gestão (Freitas; Heloani; Barreto, 2008).

Hirigoyen (2010) chama atenção para o fato de que quando o assédio é praticado por um superior, ele pode ter consequências ainda mais graves sobre a saúde da vítima, se comparado ao assédio proveniente entre os pares, uma vez que a vítima se sente ainda mais isolada e com mais dificuldade de achar a solução para o problema, pois nesse caso ela não tem a quem recorrer.

A competitividade exigida pelo mercado acaba por influenciar essa modalidade de assédio, pois as empresas estimulam que as chefias tratem de maneira hostil seus funcionários em busca de resultados. Aliado às questões de competitividade, Freitas (2001) reforça os achados de Hirigoyen (2010) e também defende o conceito das ameaças de desemprego como prática de assédio, considerando que, por medo do desemprego, os 
trabalhadores se sujeitam a condições constrangedoras e humilhantes, na tentativa de manterem seu emprego. Em um sistema de concorrência desenfreada, a gestão pautada na frieza e na dureza tornou-se um modelo, de forma que a competição inescrupulosa tem sido considerada ferramenta viável de gestão, impondo aos "fracassados" a exclusão dos processos organizacionais, visto que o mais relevante são os resultados e não a qualidade de vida do ambiente de trabalho (Hirigoyen, 2010).

Além do assédio horizontal e do vertical, Hirigoyen (2010) caracteriza outro tipo de assédio, o misto. A autora exemplifica que essa modalidade acontece mediante situações nas quais um assédio horizontal aplicado por longos períodos possa também incorporar o assédio vertical descendente, como resultado da omissão da chefia ou superior hierárquico. São situações em que o trabalhador se encontra numa posição de "bode expiatório”, tanto de um superior hierárquico, como de colegas, sendo considerado responsável por tudo o que dê errado (Rodrigues, 2013).

Também há situações em que o superior é assediado por um ou mais subordinados, esse tipo de assédio é denominado vertical ascendente. Hirigoyen (2010) relata que este ocorre com menor frequência. Para tornar mais clara a forma como esse tipo de assédio acontece, a autora cita alguns exemplos: falsa alegação de assédio sexual; movimentos coletivos utilizados como estratégia de defesa, em casos de fusões ou aquisições de novas unidades institucionais, visto que os novos dirigentes exilados necessitam de informações e aceitação de seus subordinados locais; contratação de profissionais de fora da organização para cargos de confiança e liderança, quando existia a expectativa de que um integrante da equipe fosse promovido; e até mesmo a utilização de acesso privilegiado por parte de um subordinado ao chefe de seu chefe, ou aos pares de seu chefe, para instigar maledicências, fofocas ou insinuações sobre a conduta de seu superior (Freitas; Heloani; Barreto, 2008; Rodrigues, 2013).

Vale destacar que os assediadores, independentemente da modalidade (horizontal, vertical ou mista), podem agir individualmente ou em grupo. Os grupos em geral se formam porque um determinado agressor 
pode recrutar colegas que, por receio ou interesse de ascensão ou reconhecimento, possam aliar-se a ele, tornando-se cúmplices nas ações de perseguição a um ou mais funcionários (Heloani, 2011).

Portanto, as diferentes formas em que as ações do assédio moral podem ocorrer dentro das organizações possuem em comum o cenário de competitividade dentro das instituições. A competição reforça sentimentos de hostilidade entre os funcionários da empresa, estimula a inveja e ressentimentos com relação ao outro, favorecendo um ambiente de trabalho hostil, propício à prática do assédio moral (Rodrigues; Freitas, 2014).

\section{As consequências do assédio moral}

Diante de uma temática tão ampla e complexa, o assédio moral tem-se mostrado mais abrangente, sendo que suas consequências têm ultrapassado a esfera entre a relação assediado e assediador, logo, têm fugido da restrição do campo individual para ganhar espaços ainda maiores, implicando consequências dentro da organização no que diz respeito a sua estrutura e imagem institucional, e por fim, chegando ao contexto social. Importante destacar que esse amplo alcance do assédio moral revela que seus impactos e prejuízos, arcados ou imputados em diferentes graus, podem se sobrepor (Hirigoyen, 2017; Freitas, 2007; Rodrigues, 2013; Nunes, 2016; Matos, 2016).

Hirigoyen (2017) alerta que, embora haja tamanha amplitude, não se pode banalizar o assédio, fadando-o a ser uma fatalidade à sociedade, pois ele é derivado de um modelo de gestão organizacional fundamentado em ações permissivas e alheias aos preceitos éticos. Assim, as consequências do assédio moral, baseadas nas pesquisas realizadas por Hirigoyen (2010; 2017); Freitas (2001; 2007; 2008; 2014); Heloani (2008; 2011; 2016; 2018); Bradaschia (2007); Barreto (2000; 2008; 2015; 2018); Rodrigues (2013; 2014); Damasceno (2015); Silva (2016); Matos (2016); Nunes (2016); Tavares (2017); Dantas (2018), foram descritas em três categorias: 


\section{Categoria I: As consequências do assédio moral para o indivíduo assediado}

Ao longo das pesquisas realizadas sobre o tema, observou-se que o alto preço a ser pago em decorrência do assédio moral fica a cargo do indivíduo assediado. Segundo Freitas (2007), Rodrigues (2013) e Timm (2018), a vida psicossocial do sujeito vitimado é bruscamente acometida afetando sua personalidade, identidade e autoestima, cujas consequências podem impactar as esferas psíquica, social, profissional, familiar e afetiva do indivíduo. Podem ainda comprometer sua saúde, reduzir sua capacidade de concentração, induzi-lo ao erro e colocar em xeque seu emprego ou, até mesmo, sua vida (Damasceno, 2015).

Segundo dados de pesquisas europeias e brasileiras, realizadas por Freitas (2007) e Bradaschia (2007), os trabalhos apresentam uma conta assustadora de problemas relacionados à depressão, aos pensamentos autodestrutivos e às tentativas de suicídio entre as vítimas que sofriam assédio moral no ambiente de trabalho. Outras consequências também foram descritas pelas autoras, como: afastamento do trabalho, a perda do emprego, o sentimento de nulidade e de injustiça, a descrença e a apatia, associados ao alcoolismo e ao uso de drogas (Amaral; Mendes, 2017).

Inicialmente, a vítima não consegue perceber as condutas que originam o assédio, assim, um constante mal-estar acomete o indivíduo e suas emoções (Freitas, 2007; Timm, 2018). Com o passar dos dias, os pensamentos de tristeza e confusão sobre seus próprios sentimentos tomam conta da vítima, o que muitas vezes, segundo Engelman (2015), impossibilita o assediado de tomar alguma atitude frente ao agressor, assumindo uma posição de submissão. A ideia é reforçada pelos achados de Freitas, Heloani e Barreto (2008), nos quais explicam que as emoções são marcadas por pensamentos tristes e recorrentes, a vida da vítima perde o sentido, resultando em sentimento de culpa e vergonha.

Para Hirigoyen (2010), aceitar a submissão ocasiona uma grande tensão, o que resulta em elevado estresse para a vítima. A autora segue 
afirmando que esse estado de estresse crônico pode se transformar em uma perturbação ansiosa generalizada, e em um estado de tensão e de hipervigilância permanentes. Considerando os efeitos do assédio moral sobre a saúde da vítima, a Tabela 2 destaca os estudos de Piñuel y Zabala (2003):

Tabela 2. Efeitos perniciosos sobre a saúde da vítima.

\begin{tabular}{l|l|}
\hline Sintomatologia & \multicolumn{1}{c|}{ Efeitos } \\
\hline $\begin{array}{l}\text { Efeitos cognitivos e hiper- } \\
\text { reação psíquica }\end{array}$ & $\begin{array}{l}\text { Perdas de memória; dificuldade para se concentrar; depressão; } \\
\text { apatia; irritabilidade; nervosismo/agitação; agressividade/ataques } \\
\text { de fúria; sentimento de insegurança; hipersensibilidade a atrasos. }\end{array}$ \\
\hline $\begin{array}{l}\text { Sintomas psicossomáticos } \\
\text { de estresse }\end{array}$ & $\begin{array}{l}\text { Pesadelos; dores de estômago e abdominais; diarreia/colite; vômito; } \\
\text { náuseas; falta de apetite; sensação de nó na garganta; isolamento. }\end{array}$ \\
$\begin{array}{l}\text { Sintomas de desajustes } \\
\text { do sistema nervoso } \\
\text { autônomo }\end{array}$ & $\begin{array}{l}\text { Dores no peito; sudorese; boca seca; palpitação; sufoco; falta de ar; } \\
\text { hipertensão arterial. }\end{array}$ \\
\hline $\begin{array}{l}\text { Sintomas de desgaste } \\
\text { físico resultantes de } \\
\text { estresse prolongado }\end{array}$ & Dores nas costas e nuca; dores musculares (fibromialgia). \\
\hline $\begin{array}{l}\text { Transtornos do sono } \\
\text { Cansaço e debilidade }\end{array}$ & Dificuldades para dormir; sono interrompido; acordar muito cedo. \\
\hline
\end{tabular}

Fonte: Piñuel y Zabala (2003).

Bradaschia (2007) declara que, embora esses problemas apresentados sejam suficientemente graves, é possível afirmar que não são os únicos, acredita-se que há outros efeitos que acometem a saúde física das vítimas, isso em razão de que a maioria das pesquisas encontradas agrupa as manifestações físicas sob o nome de doenças psicossomáticas.

A permanência da situação de assédio, quando prolongada, ocasiona uma desestabilização afetiva na vítima, o que segundo Freitas e Rodrigues (2014) caracteriza um estado de latência patológica em que não é possível superar o acontecido, sendo entendido assim como um novo golpe a ser enfrentado, o que vai progressivamente minando as forças do profissional. Dentre os problemas que podem surgir, as autoras destacam também a síndrome do pânico e o burnout (Matos, 2016; Timm, 2018). 
O comportamento das vítimas acaba por interferir em outras esferas de seus relacionamentos, muitas acabam reproduzindo situações de violência junto ao seio familiar e social. Outras optam por se isolar da família e de seus amigos, o que potencializa as fragilidades e amplia os efeitos e as consequências do assédio moral sofrido (Freitas; Heloani; Barreto, 2008; Matos, 2016).

O pesquisador Iñaki Piñuel y Zabala (2003) revelou que o trabalhador vítima de assédio moral pode apresentar também sintomas semelhantes aos da síndrome de estresse pós-traumático (SEPT). Esse tipo de estresse é comum em pessoas que foram vítimas de acidentes, assaltos, violações, catástrofes, dentre outros danos, porém, o que diferencia uma vítima SEPT das outras é que estas últimas sofrem o trauma uma vez e com os tratamentos adequados algumas até conseguem se superar, enquanto as vítimas de assédio moral o vivenciam repetidas vezes e, em sua maioria, não conseguem sequer se tratar.

\section{Categoria II: As consequências do assédio moral para a empresa}

De acordo com as ideias de Freitas (2007), o assédio moral no âmbito organizacional é uma silenciosa fonte de danos para as empresas. Dentre os efeitos mais comuns, podem-se destacar os prejuízos financeiros relacionados ao afastamento dos trabalhadores por doenças e acidentes de trabalho, o aumento dos custos, elevação dos índices de absenteísmo e rotatividade de pessoal, cujas consequências poderão envolver: custos com reposição de pessoal, perda de equipamentos como resultado de desconcentração dos trabalhadores, queda de produtividade em função da autoestima do grupo e do clima organizacional (Bradaschia, 2007; Rodrigues; Freitas, 2014; Matos, 2016; Amaral; Mendes, 2017).

Na última década, as empresas sentiram mais fortemente o impacto dos custos judiciais decorrentes de indenizações trabalhistas, visto que o assédio moral ganhou certa visibilidade no cenário jurídico, em razão dos 
julgados de muitas ações trabalhistas que ganharam espaço na mídia. O Tribunal Regional do Trabalho da 13a Região divulgou em sua página oficial o resultado de uma conciliação milionária realizada na $9^{a}$ Vara do Trabalho de João Pessoa no ano de 2010. Em audiência presidida pelo juiz Arnaldo José Duarte do Amaral, representantes de uma empresa, condenada por assédio moral, concordaram em pagar uma indenização no valor de mais de $\mathrm{R} \$ 1$ milhão ( $\mathrm{R} \$ 1.265 .000,00$ ) a uma ex-funcionária, acrescido de uma pensão vitalícia de $\mathrm{R} \$ 1.500,00$ mensais.

Freitas (2007) e Soboll (2008) destacam outra importante consequência para a empresa: o impacto causado em sua imagem frente aos clientes internos e externos, que causa diretamente uma desvalorização da marca.

\section{Categoria III: As consequências do assédio moral para a sociedade}

Segundo Hirigoyen (2010), o assédio moral propicia um clima de aflição, medo e fragilidade, que acaba se estendendo a toda a sociedade, uma vez que as constantes mudanças e reestruturações das empresas podem levar as pessoas a perderem a confiança em si mesmas e a adotarem uma postura de descrédito com relação ao mundo do trabalho, por se julgarem não capacitadas para enfrentar todas essas mudanças.

No contexto social, as consequências são praticamente ignoradas, embora Freitas (2007) e Rodrigues (2013) defendam que quando um indivíduo é bruscamente atingido, toda a sociedade paga o preço. Freitas (2001; 2007) relata que a incapacitação precoce das vítimas implica o aumento de despesas médicas e benefícios previdenciários, o que fatalmente abrange a esfera social. A autora relata ainda graves problemas, como: os altos índices de suicídios na sociedade nas últimas décadas; a desestruturação familiar e social das vítimas; a perda do investimento social em educação e formação profissional; os custos dos processos judiciais e a própria sobrecarga do sistema judiciário. Deve ser considerado também que o 
custo econômico dessas ações será repassado de forma indiscriminada e abusiva aos consumidores de um modo geral (Matos, 2016; Tavares, 2017).

Para Freitas, Heloani e Barreto (2008), o assédio moral vai além de uma questão exclusivamente moral, constituindo uma questão econômica e um crime que deve ser punido de maneira exemplar.

\section{Considerações finais}

A partir do presente artigo, foi possível conhecer e compreender melhor o fenômeno assédio moral tão presente nas organizações da contemporaneidade, com base nas origens e nas definições sobre o tema. Importante ressaltar que o estudo aqui ora apresentado restringiu-se a um apanhado bibliográfico decorrente do já descrito na literatura sobre os principais pesquisadores nacionais e internacionais, não havendo aprofundamento das correntes e diferentes teorias epistemológicas. Portanto, não se tratou de uma revisão sistemática da literatura, tão pouco de um estudo bibliométrico, logo, está longe de ser esgotada a busca histórica do tema.

Entretanto, este artigo foi concebido de uma problemática recorrente no ambiente organizacional, no intuito de ser mais bem estudado o assédio moral, com vista a uma investigação e aplicação futura dessa prática no ambiente educacional, mais especificamente em Instituições de Educação Superior (IES). Dessa maneira, foi possível identificar que o assédio moral é um assunto bastante estudado e pode ser praticado entre os trabalhadores de modo horizontal, vertical ou misto.

\section{Referências}

AGUIAR, André Luiz Souza. Assédio moral nas organizações: estudo de caso dos empregados demitidos e em litígio judicial trabalhista no Estado da Bahia. 2003. Dissertação (Mestrado em Administração Estratégica) — Unifacs, Salvador, 2003. Disponível em: http://www. assediomoral.org/IMG/pdf/AGUIAR_A.L.S._Assedio_moral_nas_organizacoes.pdf. Acesso em: 20 dez. 2017. 
AMARAL, Graziele Alves; MENDES, Ana Magnólia Bezerra. Readaptação Profissional de Professores como uma Promessa que não se cumpre: uma Análise da Produção Científica Brasileira. Educação em Revista, Marília, v. 18, n. 2, p.105-120, dez. 2017. Disponível em: http://www2.marilia.unesp.br/revistas/index.php/educacaoemrevista/article/view/7417. Acesso em: 10 jan. 2019.

BARRETO, Margarida Maria Silveira. Uma jornada de humilhações. 2000. 273 f. Dissertação (Mestrado em Psicologia) - Programa de Estudos Pós-graduados em Serviço Social, Pontifícia Universidade Católica, São Paulo, 2000. Disponível em: https://tede2.pucsp. br/handle/handle/17175. Acesso em: 24 jan. 2018.

BARRETO, Margarida Maria Silveira. Assédio Moral. Revista Lançamentos/Jornal Exclusivo, Porto Alegre Rio Grande do Sul, 1º abr. 2008.

BARRETO, Margarida Maria Silveira. Violência, saúde e trabalho: a intolerância e o assédio moral nas relações laborais. Serviço Social \& Sociedade, São Paulo: Cortez, n. 123, p. 544-561, set. 2015. Disponível em: http://www.scielo.br/pdf/sssoc/n123/0101-6628sssoc-123-0544.pdf. Acesso em: 4 fev. 2018.

BARRETO, Margarida Maria Silveira. Os desafios do Movimento Sindical no Combate ao Assédio Moral e Assédio Sexual. Assédio Moral e Sexual no Trabalho: como combater. 2018.

BARRETO, Margarida; HELOANI, Roberto. Assédio laboral e as questões contemporâneas à saúde do trabalhador. In: LOURENÇO, Edvânia Ângela de Souza; NAVARRO, Vera Lúcia. $O$ avesso do trabalho III: saúde do trabalhador e questões contemporâneas. São Paulo: Outras Expressões, 2013.

BARRETO, Margarida; HELOANI, Roberto. O assédio moral como instrumento de gerenciamento. In: CRESPO, Álvaro Roberto; BOTTEGA, Carla Garcia; PEREZ, Karine Vanessa. Atenção à saúde mental do trabalhador: sofrimento e transtornos psíquicos relacionados ao trabalho. Porto Alegre: Evangraf, 2014. cap. 3. p. 52-74. Disponível em: http://www.nersat.com.br/wp-content/uploads/2015/05/atencao_completo_reduzido. pdf \#page=53. Acesso em: 24 jan. 2018.

BARRETO, Margarida; HELOANI, Roberto. Violência, saúde e trabalho: a intolerância e o assédio moral nas relações laborais. Serviço Social \& Sociedade, São Paulo: Cortez, n. 123, p. 544-561, set. 2015. Disponível em: http://www.scielo.br/pdf/sssoc/n123/0101-6628sssoc-123-0544.pdf. Acesso em: 4 fev. 2018.

BOSI, Antônio de Pádua. Precarização e intensificação do trabalho no Brasil recente. Cascavel: Edunioeste, 2011.

BRADASCHIA, Carisa Almeida. Assédio moral no trabalho: a sistematização dos estudos sobre um campo em construção. 2007. 230 f. Dissertação (Mestrado em Administração de Empresas) - Escola de Administração de Empresas de São Paulo, Fundação Getúlio Vargas, São Paulo, 2007. Disponível em: http://bibliotecadigital.fgv.br/dspace/bitstream/ handle/10438/2231/50849.pdf?sequence=2. Acesso em: 24 jan. 2018. 
DAMASCENO, Thalita Natasha Ferreira. Assédio moral na universidade: a violência velada nas relações de trabalho. Curitiba: Appris, 2015.

DANTAS, Douglas Henrique Canizo. Assédio Moral na Carreira Docente. 2018. 98 f. Dissertação (Mestrado) - Curso de Mestrado Profissional em Teologia, Escola Superior de Teologia, São Leopoldo, 2018. Disponível em: https:/sucupira.capes.gov.br/sucupira/ public/consultas/coleta/trabalhoConclusao/viewTrabalhoConclusao.jsf?popup=true\&id_ trabalho=6635716. Acesso em: 7 jan. 2019.

ENGELMAN, Fernanda. Assédio Moral: vivências no mundo do trabalho. 2015. 108 f. Dissertação (Mestrado) - Curso de Mestrado em Administração, Pós-Graduação em Administração, Universidade Federal do Rio Grande do Sul, Porto Alegre, 2015. Disponível em: http://www.lume.ufrgs.br/handle/10183/132107. Acesso em: 20 jan. 2018.

EINARSEN, Ståle et al. Bullying and harassment in the workplace: developments in theory, research, and practice. 2. ed. [S. l.]: Taylor \& Francis Group, 2011. 514 p.

FREITAS, Joana Alice Ribeiro de. Violência no trabalho docente em uma universidade pública: da demanda inicial sobre assédio moral ao problema real da precarização do trabalho. 2013. 121 f. Dissertação (Mestrado em Organizações e Desenvolvimento) — FAE Centro Universitário, Curitiba, 2013. Disponível em: http://pergamum.fae.edu/pergamum/ biblioteca/index.php. Acesso em: 28 dez. 2018.

FREITAS, Joana Alice Ribeiro de. Precarização estável - Estabilidade precária: um estudo sobre a precarização do trabalho docente. In: IX Seminário do trabalho: trabalho, educação e neodesenvolvimentismo, 2014, Marília. Anais do VIII Seminário do trabalho, 2014. v. 1. p. 01-14.

FREITAS, Maria Ester de. Assédio moral e assédio sexual: faces do poder perverso nas organizações. Revista de Administração de Empresas, v. 41, n. 2, p. 8-19, jun. 2001. Disponível em: http://www.scielo.br/scielo.php?script=sci_arttext\&pid=S0034-75902001000200002. Acesso em: $20 \mathrm{dez} .2017$.

FREITAS, Maria Ester de. Quem paga a conta do assédio moral no trabalho? Revista de Administração de Empresas, São Paulo, v. 6, n. 1, p. 1-7, jan. 2007. Artigo 5. Versão eletrônica. Disponível em: http://rae.fgv.br/rae-eletronica/vol6-num1-2007/quem-pagaconta-assedio-moral-no-trabalho. Acesso em: 20 jan. 2018.

FREITAS, Maria Ester de; HELOANI, Roberto; BARRETO, Margarida. Assédio moral no trabalho. São Paulo: Cengage Learning, 2008.

HELOANI, J. R. M. Saúde mental no trabalho: algumas reflexões. In: Ana Magnólia Mendes. (Org.). Trabalho e saúde - o sujeito entre emancipação e servidão. 1. ed. Curitiba: Juruá Editora, 2008, v. 1, p. 151-183.

HELOANI, Roberto. A dança da garrafa: assédio moral nas organizações. GV-executivo, [S.l.], v. 10, n. 1, p. 50-53, mai. 2011. ISSN 1806-8979. Disponível em: http://bibliotecadigital. fgv.br/ojs/index.php/gvexecutivo/article/view/22947/21714. Acesso em: 25 jan. 2018. 
HELOANI, Roberto. Assédio moral: ultraje a rigor. Revista Direitos, Trabalho e Política Social, Cuiabá, v. 2, n. 2, p.29-42, 2016. Disponível em: http://revista91.hospedagemdesites. ws/index.php/rdtps/article/view/28. Acesso em: 9 mar. 2019.

HELOANI, Roberto; BARRETO, Margarida. Assédio moral: gestão por humilhação. Curitiba: Editora Juruá, 2018.

HIRIGOYEN, Marie-France. Assédio moral: a violência perversa no cotidiano. 16. ed. Rio de Janeiro: Bertrand Brasil, 2010.

HIRIGOYEN, Marie-France. Mal-estar no trabalho: redefinindo o assédio moral. 4. ed. — Rio de Janeiro: Bertrand Brasil, 2017.

LEYMANN, Heinz. Mobbing and psychological terror at workplaces. Violence and Victims, New York, v. 5, n. 2, p. 119-126, 1990. Disponível em: http://www.mobbingportal.com/ LeymannV\&V1990;(2).pdf. Acesso em: 24 jan. 2018.

MACIEL, Regina Heloisa et al. Auto-relato de situações constrangedoras no trabalho e assédio moral nos bancários: uma fotografia. Psicologia \& Sociedade, v. 19, n. 3, p. 117-128, dez. 2007. Disponível em: http://www.scielo.br/scielo.php?pid=S010271822007000300016\&script=sci_abstract\&tlng=pt. Acesso em: 24 jan. 2018.

MANCEBO, Deise. Trabalho docente na educação superior brasileira: mercantilização das relações e heteronomia acadêmica. Revista Portuguesa de Educação, Braga, v. 23, n. 2, p.73-91, 2010. Disponível em: http://www.scielo.mec.pt/pdf/rpe/v23n2/v23n2a04. pdf. Acesso em: 13 out. 2017.

MANCEBO, Deise; SILVA JÚNIOR, João dos Reis; OLIVEIRA, João Ferreira de. Políticas, gestão e direito à educação superior: novos modos de regulação e tendências em construção. Acta Scientiarum Education, [s.l.], v. 40, n. 1, p. 1-11, 2 fev. 2018. Universidade Estadual de Maringa. http://dx.doi.org/10.4025/actascieduc.v40i1.37669. Disponível em: https:// www.redalyc.org/articulo.oa?id=303357588007. Acesso em: 20 jan. 2019.

MATOS, Paula Adriana Lima de. O docente e as relações de trabalho na Universidade Federal de Mato Grosso: "Sofrimento e violência". 2016. 148 f. Dissertação (Mestrado) - Curso de Mestrado em Política Social, Universidade Federal de Mato Grosso, Cuiabá, 2016. Disponível em: http://www.ufmt.br/ufmt/unidade/index.php/publicacoes/index/ ppgps. Acesso em: 07 jan. 2019.

MOREIRA, Michelle Damasceno. Percepção de distúrbio de voz relacionado ao trabalho em professores da rede estadual de ensino e fatores ocupacionais associados. 2017. $150 \mathrm{f}$. Tese (Doutorado) - Curso de Doutorado em Saúde Coletiva, Universidade Estadual de Londrina, Londrina, 2017. Disponível em: https://sucupira.capes.gov.br/sucupira/public/consultas/ coleta/trabalhoConclusao/viewTrabalhoConclusao.jsf?popup=true\&id_trabalho=5615831. Acesso em: 7 jan. 2019. 
NUNES, Thiago Soares. Assédio moral no trabalho: o contexto dos servidores da Universidade Federal de Santa Catarina. 2011. 281 f. Dissertação (Mestrado em Administração) - Programa de Pós-graduação em Administração, Universidade Federal de Santa Catarina, Florianópolis, 2011. Disponível em: https://repositorio.ufsc. $\mathrm{br} /$ bitstream/handle/123456789/95904/288978.pdf?sequence=1\&isAllowed=y. Acesso em: 20 nov. 2018.

NUNES, Thiago Soares. A influência da cultura organizacional na ocorrência do assédio moral no trabalho na Universidade Federal de Santa Catarina. 2016. 432 f. Tese (Doutorado em Administração) — Universidade Federal de Santa Catarina, Florianópolis, 2016. Disponível em: https://sucupira.capes.gov.br/sucupira/public/consultas/coleta/ trabalhoConclusao/viewTrabalhoConclusao.jsf?popup=true\&id_trabalho=3713234 . Acesso em: 7 jan. 2019.

PIÑUEL Y ZABALA, Inaki. Mobbing: Como sobreviver ao assédio psicológico no trabalho. São Paulo: Edições Loyola, 2003.

RODRIGUES, Míriam. As múltiplas faces do assédio moral no ensino superior privado na perspectiva de professores dos cursos de administração de empresas na cidade de São Paulo. 2013. 270 f. Tese (Doutorado em Administração de Empresas) — Escola de Administração de Empresas de São Paulo, Fundação Getúlio Vargas, São Paulo, 2013. Disponível em: http://bibliotecadigital.fgv.br/dspace/bitstream/handle/10438/10628/ TeseMíriamRodrigues-2013.pdf?sequence=1\&isAllowed=y. Acesso em: 17 dez. 2017.

RODRIGUES, Míriam; AALTONEN, Alex. Quem dá resposta ao assédio moral? In: ENCONTRO DA ANPAD, 35., 2011, Rio de Janeiro. Anais [...]. Rio de Janeiro: Anpad, 2011. p. 1-17. Disponível em: http://www.anpad.org.br/admin/pdf/GPR8.pdf. Acesso em: 24 jan. 2018.

RODRIGUES, Míriam; FREITAS, Maria Ester de. Assédio moral nas instituições de ensino superior: um estudo sobre as condições organizacionais que favorecem sua ocorrência. Cadernos Ebape.br, Rio de Janeiro, v. 12, n. 2, p. 284-301, 2014. Disponível em: http:// www.redalyc.org/pdf/3232/323231099008.pdf. Acesso em: 17 dez. 2017.

RODRIGUES, Míriam; TEIXEIRA, Maria Luisa Mendes. Assédio moral no ambiente organizacional: proposta de mapa categorial para o estudo do fenômeno. In: IBEROAMERICAN ACADEMY OF MANAGEMENT, 6., 2009, Buenos Aires. Proceedings [...]. Buenos Aires: The Time Of Iberoamerica, 2009. p. 1-14. Disponível em: http://sistema. semead.com.br/13semead/resultado/trabalhosPDF/327.pdf. Acesso em: 20 jan. 2018.

SANTOS, Aline Veiga dos; GUIMARAES-IOSIF, Ranilce; CHAVES, Vera Lucia Jacob. Corporações privadas na educação superior brasileira: implicações das novas práticas organizacionais. Education Policy Analysis Archives, [s.l.], v. 26, p. 136-161, 15 out. 2018. Education Policy Analysis Archives. http://dx.doi.org/10.14507/epaa.26.3606. Disponível em: https://epaa.asu.edu/ojs/article/view/3606. Acesso em: 11 jan. 2019. 
SILVA, Maria Abádia da. O consenso de Washington e a privatização na educação brasileira. Linhas Criticas 21, Brasília, v. 11, n. 21, p.255-264, jun. 2005. Disponível em: https://www. redalyc.org/pdf/1935/193517360006.pdf. Acesso em: 15 jan. 2019.

SOBOLL, Lis Andréa Pereira. Violência psicológica no trabalho e assédio moral: pesquisas brasileiras. São Paulo: Casa do Psicólogo, 2008.

SOBOLL, Lis Andrea Pereira. Assédio moral e organizacional na perspectiva psicossocial: critérios obrigatórios e complementares. In: SOBOLL, Lis Andrea Pereira. Intervenções em assédio moral e organizacional. São Paulo: LTR, 2017. cap. 1. p. 13-22.

TAVARES, Francesca Stephan. O cotidiano do professor da Universidade Federal de Juiz de Fora: saúde emocional e relacional no trabalho. 2017. $141 \mathrm{f}$. Tese (Doutorado) Curso de Doutorado em Psicologia, Universidade Federal de Juiz de Fora, Juiz de Fora, 2017. Disponível em: https://sucupira.capes.gov.br/sucupira/public/consultas/coleta/ trabalhoConclusao/viewTrabalhoConclusao.jsf?popup=true\&id_trabalho=5830633. Acesso em: 7 jan. 2019.

TIMM, Jordana Wruck. O ciclo de vida profissional na docência no stricto sensu em Educação: o sentido, o significado e a percepção do bem/mal-estar a partir de narrativas (auto)biográficas. 2018. 208 f. Tese (Doutorado) - Curso de Doutorado em Educação, Pontifícia Universidade Católica do Rio Grande do Sul, Porto Alegre, 2018. Disponível em: https://sucupira.capes.gov.br/sucupira/public/consultas/coleta/trabalhoConclusao/ viewTrabalhoConclusao.jsf?popup=true\&id_trabalho=6417488. Acesso em: 7 jan. 2019.

\section{Sobre as autoras}

Carla de Fátima Nascimento Queiroz de Paula - Mestre em Gestão do Trabalho pela Universidade Santa Úrsula, Rio de Janeiro; professora em tempo parcial.

E-mail: carla.queirozdepaula@gmail.com

Ana Carolina de Gouvêa Dantas Motta - Doutora em Engenharia de Produção; professora adjunta.

E-mail: ana.motta@unigranrio.edu.br

Rejane Prevot Nascimento - Doutora em Engenharia de Produção; coordenadora e professora adjunta.

E-mail: rejaneprevot@unigranrio.edu.br 